\title{
Iron deficiency and protection of blood donors
}

Cármino Antonio De Souza

See p. $132-4$

Modern medicine should not discard the advances in blood transfusion. D ay by day, new and more intensive protocols are being developed in order to increase survival and cure rates in patients, especially those affected by cancer. M oreover, genetic diseases such as $\mathrm{H}$ emophilia $\mathrm{A}$ or $\mathrm{B}$, urban violence and traffic accidents have increased the needs related to whole blood and its components and industrially derived products.

O btaining blood supplies of sufficient quality and quantity whilepreserving the health of donors is an important challenge for the Blood Transfusion Institutions. Increasing investments have been made in serology control in order to promote recipient protection, and this is at present the main focus of donor screening. The Brazilian rules and laws are very strict in relation to serological control, and penalties are laid down for professionals and Institutions that do not carry out the determinations.

Clinical aspects like those showed in the paper "I ron D eficiency in Blood Donors" (São Paulo M ed J/Rev Paul Med 2001;119(4):132-4) are rarely studied and presented in our country, in spite of the high frequency of anemia in our population and the devel opment of an important public Blood Transfusion System. I ron deficiency is very common worldwide, especially in developing countries. In general, Brazilian blood donorsarepoor people, who have low income and nonstandard life conditions.

Several papers haveshown that depletion of iron reserves and iron dependent anemia are more frequent among blood donors, particularly among femalesand multi-timedonors. It isknown that multi-time donors are the safest blood donors. Frequent donation, performing frequent serological screening, reduces the probability of infectious diseases being transmitted by blood.

The major reason for determining thedonor's hemoglobin concentration prior to donation is to ensure either that the donor does not have pre-existing anemia or that the donor will not be made anemic by the blood donation. I ron deficiency may exist in the absence of overt anemia. $O$ ver the past decade, several studies have attempted to assess the appropriate minimum hemoglobin levels by determining the ability of proposed cutoffs to detect donors with iron deficiency in the absence of overt anemia. Unfortunately, all the proposed minimum hemoglobin levels are poorly predictive of body iron storage.

If the intent is to ensure that donors do not become iron depleted, it will be necessary to perform a more direct test for measurement of iron metabolism, such as serum ferritin, which is not readily available due to the complexity and expense of the assay. Additional attention to quality assurance of donor screening procedures is warranted due to the situations that exist in some blood transfusion settings.

Cármino Antonio de Souza, MD, PhD. Internal Medicine Department and Hematology and Blood Transfusion Center of Campinas (Hemocamp), Universidade Estadual de Campinas, São Paulo, Brazil.

\section{Address for correspondence:}

Cármino Antonio De Souza

Centro de Hematologia e Hemoterapia

Cidade Universitária, Universidade Estadual de Campinas

Distrito de Barão Geraldo

Caixa Postal 6198

Campinas/ SP - Brasil - CEP 13081-970

E-mail: carmino@obelix.unicamp.br

CO PYRIG HTO2001, Associação Paulista de Medicina 